\title{
Structural and Catalytic Properties of a Novel Vanadium Containing Solid Core Mesoporous Shell Silica Catalysts for Gas Phase Oxidation Reaction
}

\author{
N. Venkatathri ${ }^{*}$, K. Vijayamohanan Pillai ${ }^{2}$, A. Rajini ${ }^{1}$, M. Nooka Raju ${ }^{1}$ and I.A.K. Reddy ${ }^{1}$ \\ ${ }^{I}$ Department of Chemistry, National Institute of Technology, Warangal 506 004, Andhra Pradesh, India \\ ${ }^{2}$ Physical and Materials Chemistry Division, National Chemical Laboratory, Pune 411 008, Maharastra, India
}

\begin{abstract}
A novel Vanadium containing Solid core Mesoporous shell Silica catalyst was synthesized with different Si/V ratios by co-precipitation method under neutral conditions. The synthesized materials were characterized by various techniques and Gas phase Diphenyl methane oxidation reaction. The characterization reveals that a large amount of vanadium is mainly incorporated in isolated tetrahedral environment with terminal $\mathrm{V}=\mathrm{O}$ bond. Among the various Vanadium containing solid core mesoporous shell silica catalysts, the $\mathrm{Si} / \mathrm{V}=100$ ratio exhibited maximum efficiency towards Diphenyl methane to Benzophenone gas phase reaction.
\end{abstract}

Keywords: Gas phase oxidation, vanadium containing solid core mesoporous shell silica, diphenylmethane.

\section{INTRODUCTION}

Catalytic oxidation of hydrocarbons in general is employed in the manufacture of fine chemicals. In particular, more than $60 \%$ of products synthesized by catalytic routes in the chemical industry are obtained by oxidation reaction [1]. In this context, the selective partial oxidation of Diphenylmethane to Benzophenone is a versatile route for the synthesis of many fine chemicals. Since, Benzophenone is widely used as a constituent of synthetic perfumes and as a starting material for the manufacture of dyes, pesticides and drugs (especially anxiolytic and hypnotic drugs). Earlier, synthesis of Benzophenone is performed by the oxidation reaction of the Diphenylmethane using stoichiometric quantities of oxidizing agents like $\mathrm{KMnO}_{4}$ or $\mathrm{K}_{2} \mathrm{Cr}_{2} \mathrm{O}_{7}[2,3]$.

An alternative route for the production of Benzophenone is Friedel-Crafts acylation reaction of aromatics by acid halide/anhydride, using stoichiometric amounts of corrosive $\mathrm{AlCl}_{3}$ catalysts. In the above two processes, a large amount of waste is produced, and the usage of stoichiometric amount of catalysts makes the process unacceptable. The current issue is to replace the homogeneous catalysts by heterogeneous catalysts e.g. by incorporation of transition metal ions or complexes into the framework or cavities of zeolites [4], AlPOs [5], and xero or aerogels etc. [6-9]. In addition, microporous based molecular sieves have a drawback of smaller pore size, which restricts the accessibility of active sites to large substrate molecules. Thus, it is of interest to carry out the oxidation of Diphenylmethane using transition metals containing mesoporous catalysts. In this regard, new Solid core Mesoporous shell silica is recently synthesized with combined micro- and mesoporous material with uniform mesopores [10]. This remarkable interest stems from many desirable features of this mesoporous silica, including

*Address correspondence to this author at the Department of Chemistry, National Institute of Technology, Warangal 506 004, Andhra Pradesh, India; Tel: +91-9491319976; E-mail: venkatathrin@yahoo.co tailored pore size, high degree of structural ordering, larger pore size, thicker pore walls, ease of synthesis, and higher hydrothermal/ thermal stability in comparison to MCM-41, MCM-48, SBA-15 and HMS mesoporous materials. In addition to that the porogen employed to obtain this Solid core Mesoporous shell silica, Octadecyltrimethoxy silane is cheaper than the surfactants used initially in the synthesis of MCM-41 and SBA-15 [11-14].

In the recent past, Vanadium-substituted molecular sieves have been found to be excellent catalysts for many selective oxidation reactions [15-18]. The catalytic activity and selectivity of vanadium-substituted molecular sieves are directly related to the co-ordination structures of the vanadium species in the molecular sieves. Since, research had taken great effort to synthesis of vanadium containing mesoporous molecular sieves for bulkier molecule transformation. In this regard, attempts have been taken to synthesize vanadium containing mesoporous molecular sieves by adopting different methods. These methods include ion grafting [19], direct hydrothermal synthesis [20], impregnation [21], and molecular designed dispersion [22]. Despite its potential, there are no reports on the direct synthesis of Vanadium containing Solid core mesoporous shell silica.

For many oxidation reactions, it is always desirable to choose air as oxidant due to its availability in the nature and there by carrying out the reaction in gas phase, it is possible to avoid the leaching of metal from the framework with the solvent free condition [23]. Therefore, the gas-phase oxidation of organic compounds over heterogeneous catalysts is environmentally benign from the viewpoint of "green chemistry" [24, 25].

In the present investigation, synthesis of novel Vanadium containing Solid core Mesoporous shell silica by coprecipitation method is established and its application towards vapor phase oxidation of Diphenylmethane using $\mathrm{CO}_{2}$ free air as oxidant. In order to achieve the better activity 
and selectivity, effect of temperature, time on stream, and vanadium content were studied.

\section{EXPERIMENTAL}

The Vanadium containing Solid core mesoporous shell silica was synthesized by co-precipitation method using the following procedure. $74 \mathrm{ml}$ of Acetone $(99.5 \%$, s.d.fine, India) was mixed with $11 \mathrm{ml}$ of Tetraethylortho silicate (98 $\%$, Aldrich, USA). $3.3 \mathrm{ml}$ of Triethylamine ( $98 \%$, s.d.fine, India) and $2 \mathrm{ml}$ of Octadecyltrichlorosilane ( $98 \%$, Aldrich, USA) were mixed with the above gel. $0.102 \mathrm{~g} \mathrm{~V}_{2} \mathrm{O}_{5}(98 \%$, Aldrich, USA) was mixed well with the above mixture. Finally $10 \mathrm{ml}$ distilled water was mixed and stirred well for 2 $\mathrm{h}$. The precipitate is centrifuged to separate the solid and washed with distilled water and dried at $353 \mathrm{~K}$. The assynthesized sample was subjected to various physicochemical characterizations. A portion of the sample was calcined at $823 \mathrm{~K}$ for $8 \mathrm{~h}$ and the furnace temperature was raised from room temperature at $1.5 \mathrm{~K} / \mathrm{min}$ rate. Influence of various silanes were studied in similar conditions.

Small angle X-ray diffraction analysis was carried out using Mac Science Co. Ltd., MO3XHF22 instrument in the $1-12^{\circ}$ region. The surface elemental analysis and particle size and shape were analyzed by a Leica Stereoscan - 440 scanning electron microscope. The copper disc was pasted with carbon tape and the sample was dispersed over the tape. The disc was coated with gold in ionization chamber. Transmission electronmicroscopic (TEM) studies were performed on a JEOL JSM-2000 EX electron microscope operated at $200 \mathrm{kV}$. The TEM sample was prepared by dipping a $\mathrm{Cu}$ grid coated with carbon films in sample suspension with water as solvent (solution was sonicated for $20 \mathrm{~min}$ ). Thermogravimetry/Differential thermal analysis was carried out using Perkin Elmer, S11 Diamond TG/DTA analyzer. Fourier transform Infrared spectroscopic analysis was carried out using Perkin Elmer Spectrum one FT-IR Instruments. Electron spin resonance spectra of the assynthesized and calcined Vanadium containing Solid core Mesoporous shell silica samples were obtained using a Bruker 200D spectrometer. The UV-Vis diffuse reflectance spectra were recorded using a Pye Unichem (SP-8-100) instrument in 200-900 $\mathrm{nm}$ regions. X-ray Photoelectron spectroscopic analysis carried out using ESCA-3000 (VG Scientific, UK) instrument. Cyclic voltammetric analysis was carried out using Solaratron S1 1287 Electrochemica interface and Solaratron 1255B Frequency Response analyzer. Solid State Nuclear Magnetic Resonance spectrum is carried out using Bruker Avance $300 \mathrm{MHz}$ instrument.

Oxidation of Diphenylmethane was carried out on a fixed bed down flow quartz reactor with $\mathrm{CO}_{2}$ free air at atmospheric pressure in the temperature range of $563-713 \mathrm{~K}$ (Scheme 1). Prior to the reaction, the reactor was charged with $0.5 \mathrm{~g}$ of the catalyst and preheated in a tubular furnace equipped with a thermocouple. Diphenylmethane was fed into the reactor through a syringe infusion pump at a predetermined flow rate. The product mixture was collected at regular interval of time was filtered through $0.2 \mu \mathrm{m}$ membrane filter and analyzed by HPLC (Shimadzu, CLASS VP model) with a UV detector using a column packed with octadecyl silane with a mobile phase of acetonitrile/

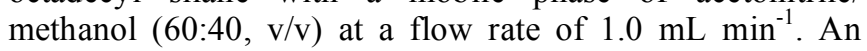

injection volume of $20 \mu \mathrm{l}$ was used. After every run, the catalysts were regenerated by passing a stream of pure dry air at a temperature of $773 \mathrm{~K}$ for $6 \mathrm{~h}$.
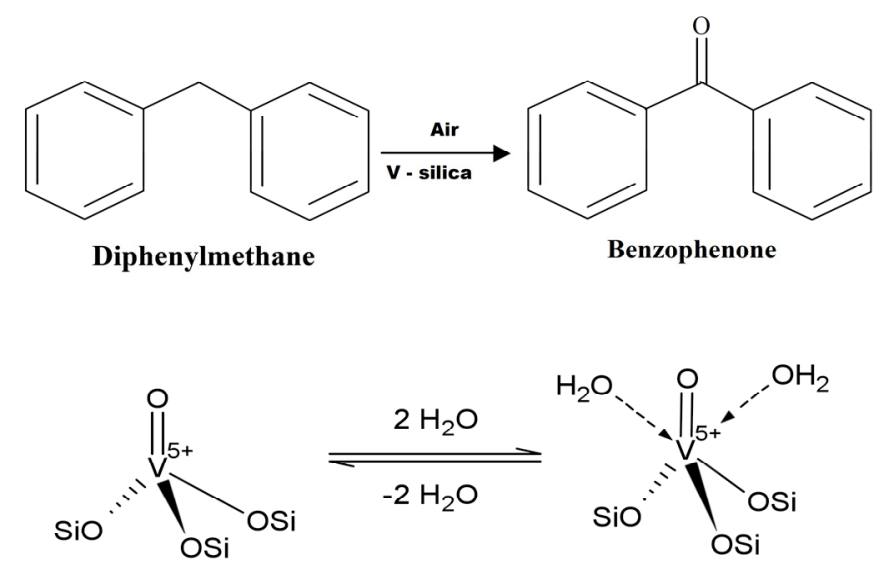

Scheme 1. Vapour phase oxidation of Diphenylmethane.

\section{RESULTS AND DISCUSSION}

Presence and absence of Octadecyltrichlorosilane and Triethylamine along with other ingredients give solid precipitate (Table 1). However use of Methyltrimethoxysilane and Octyltrimethoxy silane instead of Octadecyltrichlorosilane did not give precipitate. The reason is probably due to the enhanced hydrolyzing rate in Octadecyltrichlorosilane. The small angle X-ray diffraction pattern (Fig. 1) of the assynthesized Vanadium containing Solid core mesoporous shell silica show that they are probably mesoporous. On calcinations the pattern does not change considerably, however a small line broadening is observed. Scanning electron micrograph of Vanadium containing Solid core mesoporous shell shows the morphology of pure solid core Mesoporous shell silica and Vanadium containing solid core mesoporous shell silica are spherical, however the particle size are 400 and $500 \mathrm{~nm}$. The Transmission electron micrograph of the calcined samples shows $400 \mathrm{~nm}$ (shell size $45 \mathrm{~nm}$ ) and $500 \mathrm{~nm}$ (shell size $50 \mathrm{~nm}$ ) for Vanadium free and Vanadium containing solid core mesoporous silica shell samples (Fig. 2). E-DAX analysis (Table 1) of the assynthesized samples shows the presence of larger extent of Octadecyltrichlorosilane and Triethylamine in surface of the Solid core Mesoporous shell silica. It is deduced that from the above analysis, the larger surface area of the calcined materials are due to the vacant sites created by the loss of these species. The presence of large extent of Octadecyltrichlorosilane is available not only in surface, but also in bulk is observed from the Thermogravimetry/Differential thermal analysis. It shows about $60 \%$ exothermic weight loss on calination in presence of air from room temperature to $900{ }^{\circ} \mathrm{C}$.

Typical nitrogen adsorption isotherms at $77 \mathrm{~K}$ (Fig. 3) show a linear increase in the amount of adsorbed nitrogen at low pressures $(\mathrm{P} / \mathrm{Po}=0.5)$. The resulting isotherm can be classified as a type II isotherm with a type $\mathrm{H} 2$ hysteresis, according to the IUPAC nomenclature [26-29]. The steep increase in nitrogen uptake at relative pressures in the range between $\mathrm{P} / \mathrm{Po}=0.40$ and 0.60 is reflected in a narrow pore size distribution. Thus, the variation of the catalyst in the 
Table 1. Physical Properties of Mesoporous V - Silica

\begin{tabular}{|c|c|c|c|c|}
\hline S. No. & Gel Composition & Product Composition (2 h) & Particle Size & Yield (\%) \\
\hline \hline 1. & $0.01 \mathrm{~V}_{2} \mathrm{O}_{5}: \mathrm{SiO}_{2}: 0.7$ TEA: 0.1ODTCS: $11.5 \mathrm{H}_{2} \mathrm{O}: 1.25 \mathrm{Act}$ & $\mathrm{SiO}_{2}: 0.02 \mathrm{~V}_{2} \mathrm{O}_{5}: 0.3 \mathrm{TEA}: 0.04 \mathrm{ODTCS}$ & $500 \mathrm{~nm}$ (shell thickness $=50 \mathrm{~nm})$ & 100 \\
\hline 2. & $\mathrm{SiO}_{2}: 0.7 \mathrm{TEA}: 0.1 \mathrm{ODTCS}: 11.5 \mathrm{H}_{2} \mathrm{O}: 1.25 \mathrm{Act}$ & $\mathrm{SiO}_{2}: 0.3 \mathrm{TEA}: 0.04 \mathrm{ODTCS}$ & $400 \mathrm{~nm}($ shell thickness $=45 \mathrm{~nm})$ & 80 \\
\hline 3. & $0.01 \mathrm{~V}_{2} \mathrm{O}_{5}: \mathrm{SiO}_{2}: 0.7 \mathrm{TEA}: 11.5 \mathrm{H}_{2} \mathrm{O}: 1.25 \mathrm{Act}$ & $\mathrm{SiO}_{2}: 0.06 \mathrm{~V}_{2} \mathrm{O}_{5}: 0.3 \mathrm{TEA}$ & $600(\mathrm{no}$ shell) & 70 \\
\hline 4. & $0.01 \mathrm{~V}_{2} \mathrm{O}_{5}: \mathrm{SiO}_{2}: 0.7$ TEA: $0.1 \mathrm{R}: 11.5 \mathrm{H}_{2} \mathrm{O}: 1.25 \mathrm{Act}$ & No precipitate & - & - \\
\hline
\end{tabular}

Synthesis conditions: Duration $=2 \mathrm{~h}$, Temperature $=298 \mathrm{~K}$, Rotation $=650 \mathrm{rpm}$. TEA : Triethylamine, ODTCS : Octadecyltrichloro silane, Act : Acetone, R : Octadecyltrimethoxy silane, Methyltrimethoxy silane, Octyltrimethoxy silane.

(A)

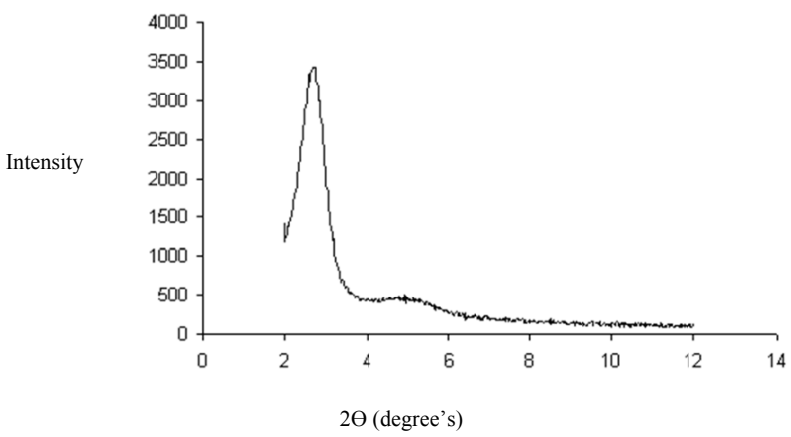

(B)

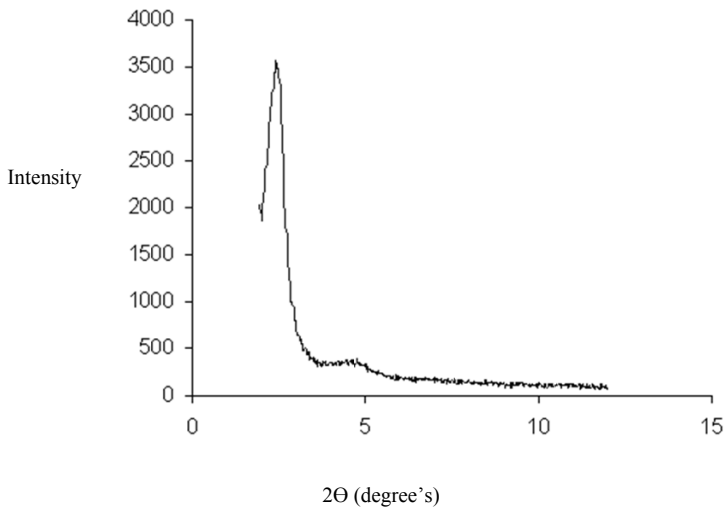

Fig. (1). The low angle X-ray diffraction patterns of Vanadium containing solid core mesoporous shell silica $(\mathrm{Si} / \mathrm{V}=100)$ catalyst in (A) as-synthesized and (B) calcined form.

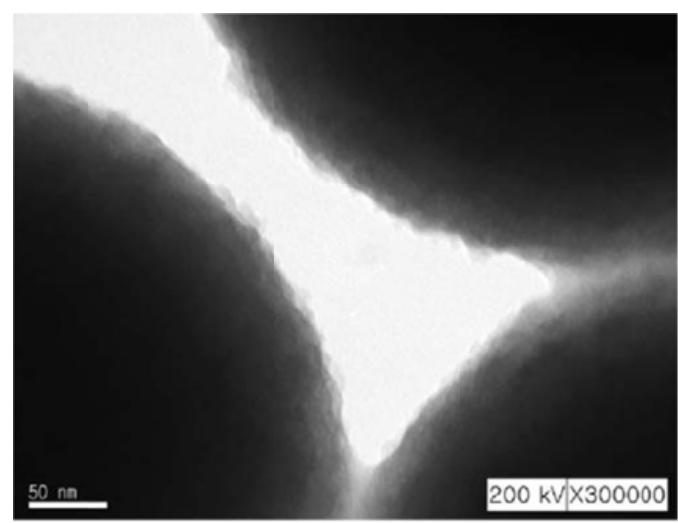

A solution during the growth process enables one to adjust and to control pore structural parameters such as the specific surface area, $550 \mathrm{~m}^{2} / \mathrm{g}$, specific pore volume $1.29 \mathrm{~cm}^{3} / \mathrm{g}$, average pore diameter, $239 \AA$ and medium pore width, 302 $\AA$.

Fourier transform Infrared spectrum of the as-synthesized sample shows that peaks around 1700 and $3430 \mathrm{~cm}^{-1}$ corresponding to the carboxyl and hydroxyl groups [30] respectively. The adsorption peak belonging to the Si-O stretching vibration of Si-O-O $\mathrm{M}^{+}$bond appears at $960 \mathrm{~cm}^{-1}$ [31]. The weak peaks at 2855 and $2920 \mathrm{~cm}^{-1}$ belong to the stretching vibrations of $\mathrm{C}-\mathrm{H}$ bonds, which show a few organic groups are adsorbed on the spheres. The strong peaks near 1100, 802 and $467 \mathrm{~cm}^{-1}$ agree to the Si-O-Si bond which implies the condensation of silicon alkoxide [31].

Diffuse reflectance Ultra violet - visible spectra of as synthesized sample shows (Fig. 4) peaks at 350, $280 \& 220$ $\mathrm{nm}$. The peak at $220 \mathrm{~nm}$ is due to $\mathrm{Si}^{-} \mathrm{O}^{-}$species and peak at $280 \mathrm{~nm}$ is due to tetrahedrally coordinated $\mathrm{V}^{5+}$ species and peak at $350 \mathrm{~nm}$ is due to blue shifted square pyramidal Vanadium species $[32,33]$. Calcined sample shows a single broad peak at $460 \mathrm{~nm}$ corresponds to $\mathrm{V}^{5+}$ in square pyramidal environments $[34,35]$.

The electron spin resonance spectra (Fig. 5) of the Vanadium containing as-synthesized sample shows a eight line hyperfine splitting with $\mathrm{A}_{11}=198, \mathrm{~g}_{11}=1.9293, \mathrm{~A}_{\perp}=78$ and $\mathrm{g}_{\perp}=1.9814$ parameters correspond to $\mathrm{VO}^{2+}$ in a distorted octahedral or square pyramidal environment [36-41]. On calcinations most of the vanadium is oxidized to $\mathrm{V}^{5+}$ ions and the eight-line hyperfine splitting intensity reduced to one

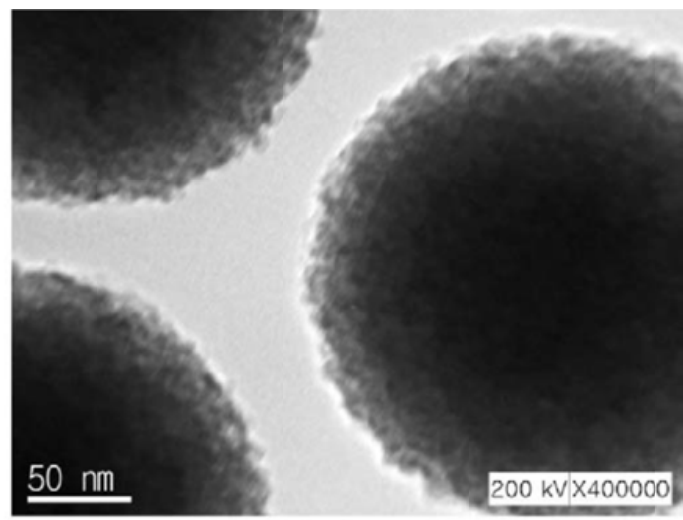

B

Fig. (2). Transmission electron micrograph of calcined (A) Solid core mesoporous shell silica and (B) Vanadium containing solid core mesoporous shell silica $(\mathrm{Si} / \mathrm{V}=100)$ catalyst. 
fifth of the original peak intensity. Thermal reduction with hydrogen gave ESR spectrum similar to that of the assynthesized sample, but the intensity was one third of that of the as-synthesized form. This clearly demonstrates the redox behavior of the vanadium present in the samples.

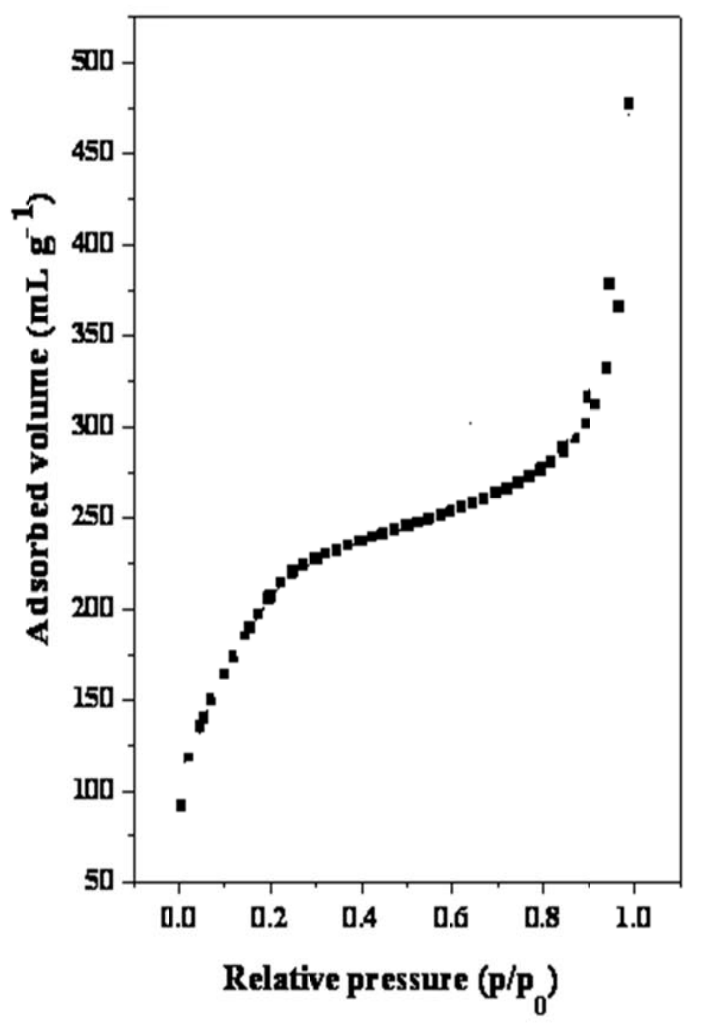

Fig. (3). $\mathrm{N}_{2}$ adsorption - desorption isotherms of calcined Vanadium containing solid core mesoporous shell silica $(\mathrm{Si} / \mathrm{V}=$ 100) catalyst.

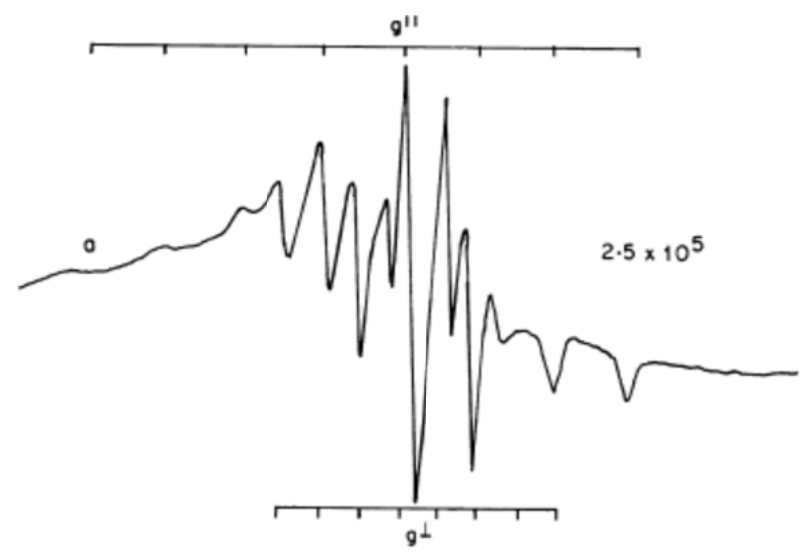

Fig. (4). Electron spin resonance spectrum of as-synthesized Vanadium containing solid core mesoporous shell silica $(\mathrm{Si} / \mathrm{V}=$ 100) catalyst.

The X-ray Photoelectron spectra of as-synthesized sample in $\mathrm{V}_{2 \mathrm{p}}$ region (528-540 eV) are shown in Fig. (6) shows two peaks, one is corresponding to $\mathrm{V}^{4+}$ at $528 \mathrm{eV}$ shows d other one corresponding to $\mathrm{V}^{5+}$ at $539 \mathrm{eV}$ [42]. This shows that as-synthesized sample contains both $\mathrm{V}^{4+}$ and $\mathrm{V}^{5+}$ species, among them $\mathrm{V}^{5+}$ content is more.

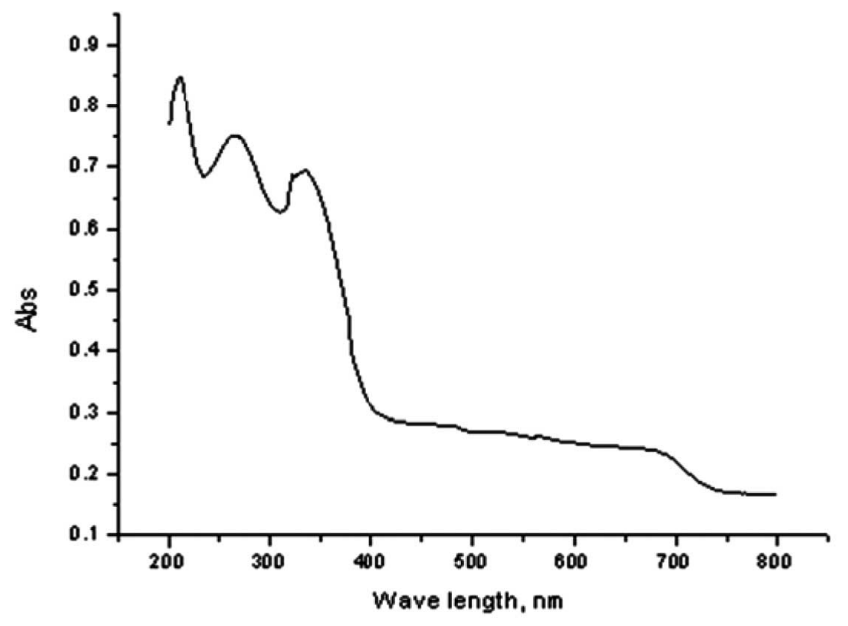

Fig. (5). Diffuse reflectance Ultraviolet - visible spectrum of assynthesized Vanadium containing solid core mesoporous shell silica $(\mathrm{Si} / \mathrm{V}=100)$ catalyst.

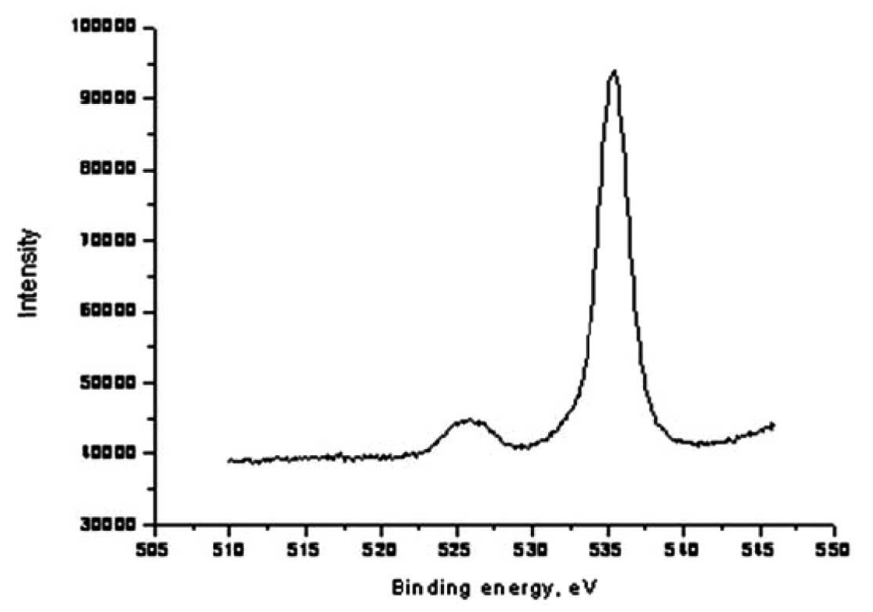

Fig. (6). X-ray photoelectron spectrum of as-synthesized Vanadium containing solid core mesoporous shell silica $(\mathrm{Si} / \mathrm{V}=100)$ catalyst.

Castro-Martins et al. $[43,44]$ have used cyclic voltammetric techniques to prove the presence of $\mathrm{Ti}^{4+}$ ions in the frameworks of TS-1 and TS-2. Venkatathri and coworkers have extensively investigated VS-1. VS-2, VAPO-5 and V-Al- $\beta[44,45]$. The cyclic voltammetry of Vanadium containing solid core mesoporous shell silica shows one redox couple of peaks between $+0.6 \mathrm{~V}$ to $-0.2 \mathrm{~V}$. It was suggested earlier that the redox couple were due to $\mathrm{V}^{5+} / \mathrm{V}^{4+}$ redox couple originated from $\mathrm{V}^{5+}$ present in as-synthesized samples $[45,46]$ with distorted tetrahedral symmetry.

Fig. (7) shows the ${ }^{29} \mathrm{Si}$ Magic angle spinning Nuclear magnetic resonance spectrum of Vanadium containing solid core mesoporous shell silica, which contains four distinct lines at $-107,-93$ and $-60 \&-53 \mathrm{ppm}$ in as-synthesized sample and on calcination the peaks at -60 and -53 ppm intensities are disappeared. The four peaks present in assynthesized samples are due to $\mathrm{Si}: 4 \mathrm{Si}, \mathrm{Si}: 2 \mathrm{~V}$ : $2 \mathrm{Si}$ and $\mathrm{Si}$ : 3C: Si and Si: 2C: Si species [47-51]. 
(A)

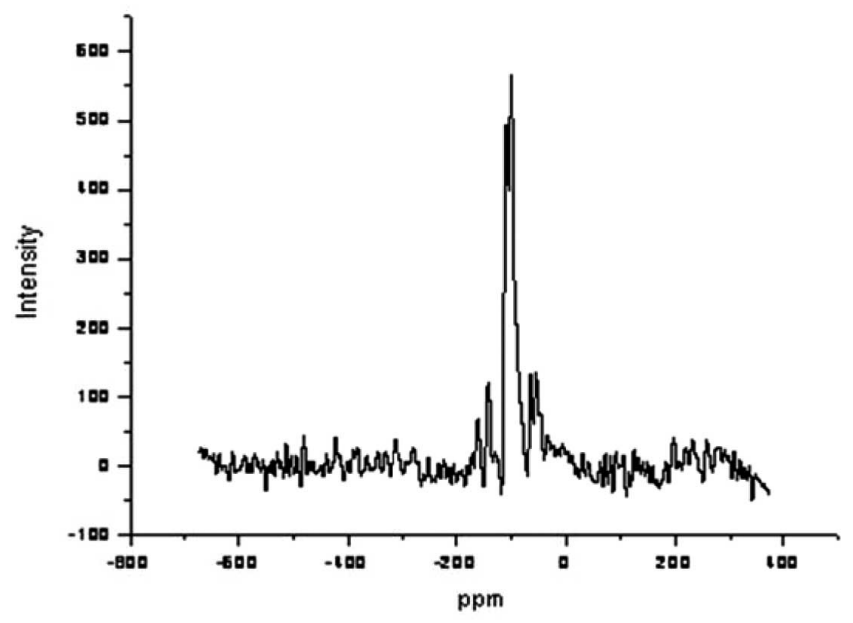

(B)

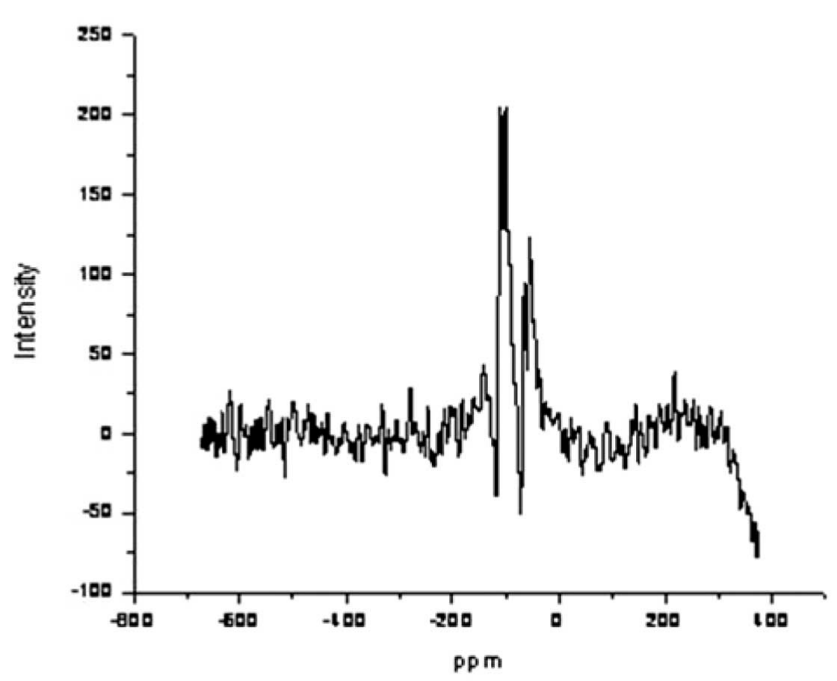

Fig. (7). ${ }^{29} \mathrm{Si}$ Magic angle spinning Nuclear Magnetic Resonance spectra of A) as-synthesized, B) calcined Vanadium containing solid core mesoporous shell silica $(\mathrm{Si} / \mathrm{V}=100)$ catalyst.

The effect of vanadium content on Vanadium containing solid core mesoporous shell silica catalysts for Diphenylmethane to Benzophenone conversion and selectivity was carried out at optimized reaction conditions. The feed ratio of Diphenylmethane to molecular oxygen from air was set at $1: 4$ (molar ratio) and that of WHSV as $4 \mathrm{~h}^{-1}$. Typically, the Diphenylmethane conversion was increased with decreasing $\mathrm{Si} / \mathrm{V}$ ratios from 200 to 100 .

The vapor phase oxidation of Diphenylmethane using $\mathrm{CO}_{2}$ free air as oxidant was carried out on fixed bed down flow reactor operating at atmospheric pressure at different temperature ranging from 563 to $713 \mathrm{~K}$ over $\mathrm{Si} / \mathrm{V}=100$ ratio Vanadium containing solid core mesoporous shell silica catalyst for $2 \mathrm{~h}$. The molar feed ratio of Diphenylmethane to molecular oxygen (from Air) was set as 1:4 with WHSV (Weight hourly space velocity) of Diphenylmethane as $4 \mathrm{~h}^{-1}$. It could be seen from Fig. (8) that as the temperature increased from 563 to $713 \mathrm{~K}$ the conversion of Diphenylmethane gradually increased and Benzophenone selectivity was drastically reduced due to by products. This observation was further verified by mass balance calculation. The optimum temperature for better conversion and selectivity was found to be $593 \mathrm{~K}$.

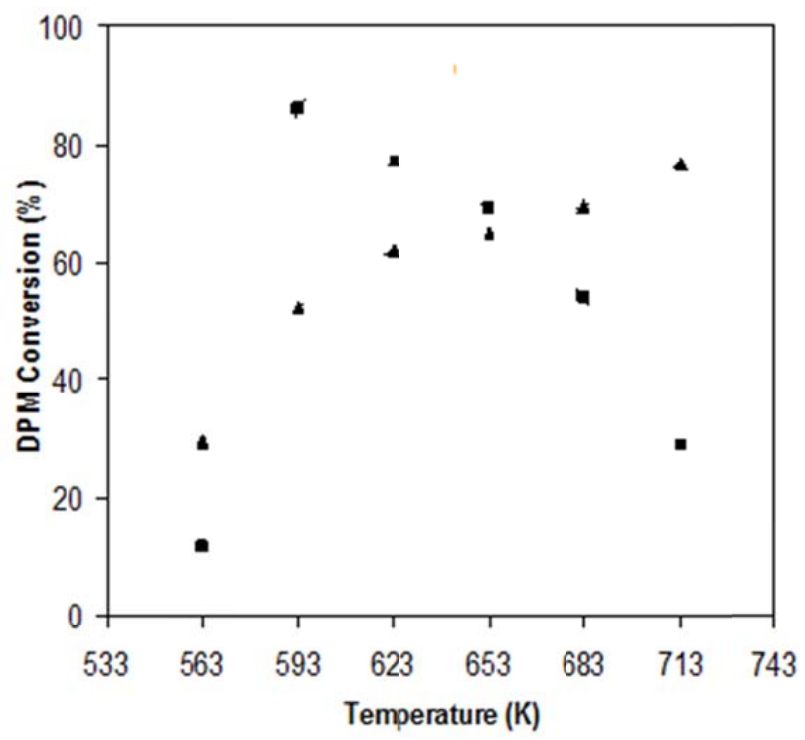

Fig. (8). Effect of temperature on the conversion $(\Delta)$ and selectivity (ם) of diphenylmethane, Reaction conditions: Weight of the catalyst $0.5 \mathrm{~g}$; WHSV; $4 \mathrm{~h}^{-1}$; Flow rate of DPM to Air 1:4 (mole ratio); Reaction time; $2 \mathrm{~h}$. Catalyst: Vanadium containing solid core mesoporous shell silica $(\mathrm{Si} / \mathrm{V}=100)$ catalyst.

The effect of time on the conversion and selectivity over $\mathrm{Si} / \mathrm{V}=100$ catalyst was studied at $593 \mathrm{~K}$, Diphenylmethane to molecular oxygen (from air) molar ratio is 1:4 and WHSV of Diphenylmethane is $4 \mathrm{~h}^{-1}$. The observed results are illustrated in Fig. (9). The conversion and selectivity are remains same without significant change. It also demonstrate that there was no coke blocked the pores. The conversion and selectivity was almost similar with regenerated catalysts.

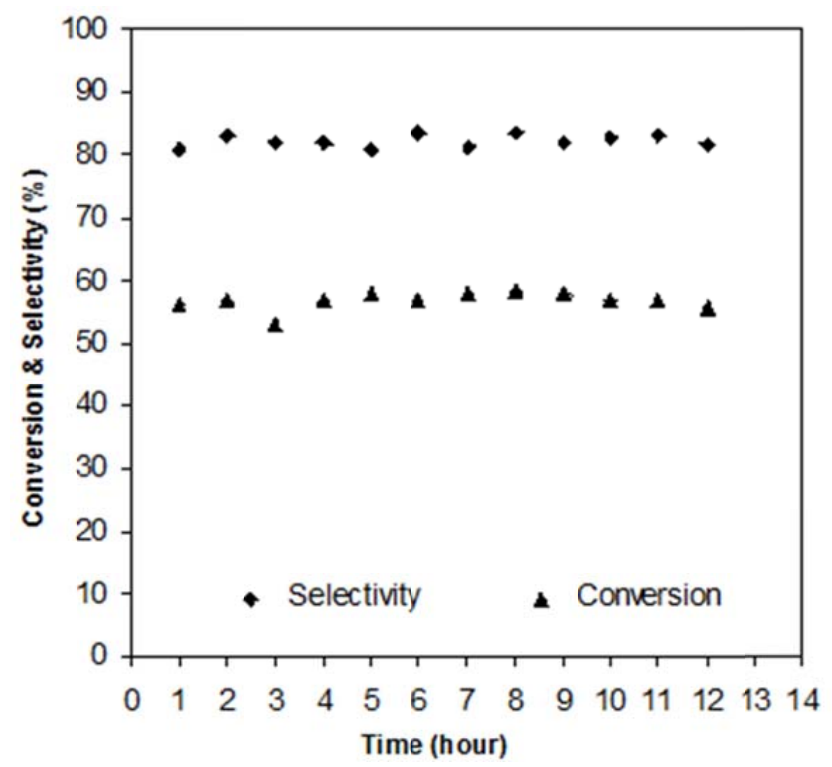

Fig. (9). Effect of reaction time on Diphenylmethane conversion and Benzophenone selectivity, Reaction conditions: Weight of the catalyst: $0.5 \mathrm{~g}$; Temperature: $593 \mathrm{~K}$; WHSV: $4 \mathrm{~h}^{-1}$; Flow rate of DPM to Air 1:4 (mole ratio); Catalyst: Vanadium containing solid core mesoporous shell silica $(\mathrm{Si} / \mathrm{V}=100)$ catalyst. 
The influence of contact time on conversion and selectivity was studied at optimum conditions and 0.05 to $0.25 \mathrm{~h}^{-1}$. The conversion is increased linearly with increasing the contact time from 0.05 to 0.25 . The selectivity remains same even at lower contact time.

\section{CONCLUSIONS}

In summary, novel Vanadium containing solid core mesoporous shell silica catalysts for Diphenyl methane gas phase oxidation were synthesized and characterized. The activity profiles are clearly shown that the conversion increases with increasing vanadium content. The isolated tetrahedral vanadium species (Scheme 1) are found to be responsible for the catalytic activity. It is proposed that the Diphenyl methane is oxidized by peroxide radical mechanism. Such a species will be formed easily, only when the Vanadium is in tetrahedral co-ordination as given in the scheme.

\section{ACKNOWLEDGEMENTS}

One of the author N.V would like to thank the Indian academy of Sciences, Bangalore for a summer research fellowship.

\section{CONFLICT OF INTEREST}

Declared done.

\section{REFERENCES}

[1] Hutchings, G.J.; Scurrell, M.S. Designing oxidation catalysts: Are we getting better? Cattech, 2003, 7, 90-103.

[2] Cullis, C.F.; Ladbury, J.W. Kinetic studies of oxidation of aromatic compounds by potassium permanganate III : Ethyl Benzene. $J$. Chem. Soc., 1955, 2850-2854.

[3] Clark, J.H.; Kybett, A.P.; Landon, P.; Macquarrie, D.J.; Martin, K. Catalytic oxidation of orgajic substrates using alumina supported Chromium and Manganese. J. Chem. Soc., Chem. Commun., 1989, $1355-1356$.

[4] Robert Adams, C.; Xu, L.; Moller, K.; Bein, T.; Nicholas Delgass, W. Zeolite encapsulated vanadium oxo species for the catalytic reduction of $\mathrm{NO}$ by $\mathrm{NH}_{3}$. Catal. Today. 1997, 33, 263-278.

[5] Blasco, T.; Concepcion, P.; Grotz, P.; Lopez Nieto, J.M.; MartinezArias, A. On the nature of $\mathrm{V}$ and $\mathrm{Mg}$ containing $\mathrm{AlPO}_{4}-5$ catalysts. J. Mol. Catal. A: Chem. 2000, 162, 267-273.

[6] Spinaceé, E.V.; Schuchardt, U.; Cardoso, D. Oxidation of hydrocarbons with peroxides catalyzed by Chromium (III) and Iron (III) incorporated in SAPO-37 framework. Appl. Catal. A: General., 1999, 185, 193-197.

[7] Pinnavaia, T.J.; Tzou, M.S.; Landau, S.D. New chromia pillared clay catalysts. J. Am. Chem. Soc., 1985, 107, 4783-.4785.

[8] Klein, S.; Martens, J.A.; Parton, R.; Vercruysse, K.; Jacobs, P.A.; Maier, W.F. Amorphous microporous mixed oxides as selective redox catalysts. Catal. Lett., 1996, 38, 209-214.

[9] Hutter, R.; Mallat, T.; Baiker, A. Titania silica mixed oxides- II: Catalytic behaviour in olefin epoxidation. J. Catal. 1995, 153, 177189.

[10] Buchel, G.; Unger, K.K.; Matsumoto, A.; Tsutsumi, K. A novel pathway for synthesis of submicrometer-size solid core/mesoporous shell silica spheres. Adv. Mater., 1998, 10, 10361038.

[11] Bennadja, Y.; Beaunier, P.; Margolese, D.; Davidson, A. Fine tuning of the interaction between pluronic surfactants and silica walls in SBA-15 babistryctyred nateruaks. Micropor. Mesopor. Mater., 2001, 44-45, 147-152.

[12] Kruk, M.; Jaroniec, M.; Ko, C.H.; Ryoo, R. Characterization of the porous structure of SBA-15. Chem. Mater., 2000, 12, 1961-1968.

[13] Cassiers, K.; Linssen, T.; Mathieu, M.; Benjelloun, M.; Schrijnemakers, K.; Van Der Voort, P.; Cool, P.; Vansant, E.F. A detailed stury of thermal, hydrothermal and mechanical stabilities of a wide range of surfactant assembled mesoporous silicas. Chem. Mater., 2002, 14, 2317-2324.
[14] Zhao, D.; Huo, Q.; Feng, J.; Chmelka, B.F.; Stucky, G.D. Nonionic Triblock and star Diblock copolymer and oligomeric surfactant syntheses of Highly ordered, Hydrothermally stable mesoporous silica structures. J. Am. Chem. Soc., 1998, 120, 6024-6036.

[15] Venkatathri, N. Synthesis, characterization and catalytic properties of Vanadium aluminophosphate molecular sieves VAPO-31 and VAPO-Amr from non-aqeous media. Appl. Catal. A: Gen., 2006, 310,31-39.

[16] Weckhuysen, B.M.; Keller, D.E. Chemistry, Spectroscopt and the role of supported vanadium oxides in heterogeneous catalysts. Catal. Today, 2003, 78, 25-46.

[17] Piumetti, M.; Bonelli, B.; Armandi, M.; Gaberova, L.; Casale, S.; Massiani, P.; Garrone, M. Vanadium containing SBA-15 systems prepared by direct synthesis : Physico-chemical and catalytic properties in the decomposition of dichloromethane. Micropor. Mesopor. Mat., 2010, 133, 36-44.

[18] George, J.; Shylesh, S.; Singh, A.P. Vanadium containing ordered mesoporous silicas : Synthesis, characterization and catalytic activity in the hydroxylation of biphenyl. App. Catal. A: General, 2005, 290, 148-158.

[19] Du, S.; Lim, S.; Pinault, M.; Wang, C.; Fang, F.; Pfefferle, L.; Haller, G.L. Synthesis, characterization and catalytic performance of highly dispersed vanadium grafted SBA-15 catalyst. J. Catal., 2008, 253, 74-90.

[20] Gao, F.; Zhang, Y.; Wan, H.; Kong, Y.; Wu, X.; Dong, L.; Li, B.; Chen, $\mathrm{Y}$. The states of vanadium species in V-SBA-15 synthesized under different $\mathrm{pH}$ values. Micropor. Mesopor. Mater., 2008, 110, $508-516$

[21] Fornes, V.; Lopez, C.; Lopez, H.H. Martınez, A. Catalytic performance of mesoporous $\mathrm{VO}_{\mathrm{x}} / \mathrm{SBA}-15$ catalysts for the partial oxidation of methane to formaldehyde. Appl. Catal. A: Gen., 2003, 249, 345-354.

[22] Kustrowski, P.; Segura, Y.; Chmielarz, L.; Surman, J.; Dziembaj, R.; Cool, P.; Etiennem, Vansant, F. VO $_{\mathrm{x}}$ supported SBA-15 catalysts for the oxydative dehydrogenation of ethyl benzene to styrene in the presence of $\mathrm{N}_{2} \mathrm{O}$. Catal. Today, 2006, 114, 307-313.

[23] Santhanaraj, D.; Suresh, C.; Vijayan, P.; Venkatathri, N.; Shanthi, K. Mn-MCM-41 molecular sieve: a selective gasphase cyclohexanol oxidation catalyst. React. Kinet. Mech. Catal., 2010, 99, 439-446.

[24] Takehira, K.; Shishido, T.; Song, Z.; Matsushita, T.; Kawabata, T.; Takaki,T. Crystalline $\mathrm{CrV}_{0.95} \mathrm{P}_{0.05} \mathrm{O}_{4}$ catalyst for the vapor phase oxidation of picolines. Catal. Today, 2004, 91, 7-11.

[25] Mahendiran, C.; Vijayan, P.; Basha, S.J.; Sangeetha, P.; Shanthi, K. Vapor phase oxidation of tetralin over $\mathrm{Cr}$ and $\mathrm{Fe}$ substituted MCM41 molecular sieves. J. Mol. Catal. A: Chem., 2006, 275, 84-90.

[26] Fujiwara, M.; Shiokawa, K.; Tanaka, Y.; Nakahara, Y. Preparation and formation mechanism of silica microcapsules (Hollow sphere) by water/oil/water Interfacial reaction. Chem. Mater., 2004, 16, 5420-5426.

[27] Brunauer, S.; Deming, L.S.; Deming, W.S.; Teller, E. On a theory of the vander waals adsorption of Gases. J. Am. Chem. Soc., 1940 62, 1723-1732.

[28] de Boer, J.H. The Structure and Properties of Porous Materials. Butterworths, London, 1958.

[29] IUPAC, Reporting Physisorption Data for Gas/Solid Systems. Pure Appl. Chem., 1957, 87(1), 603-608.

[30] Shan, Y.; Gao, L.; Zheng, S. A facile approach to load CdSe nanocrystallites in to mesoporous SBA-15. Mater. Chem. Phys., 2004, 88, 192-196.

[31] Agger, J.R.; Anderson, M.W.; Pemble, M.W.; Terasaki, O.; Nozue, Y. Growth of quantum-confined Indium Phosphide MCM-41. $J$. Phys. Chem. B, 1998, 102, 3345 .

[32] Lischke, G.; Hanke, W.; Jerschkewitz, H.G.; Ohlmann, J. Investigations of catalytically active surface compounds XVII: Influence of size and structure of Vanadium oxide clusters on selectivity in the oxidation of n-butene. J. Catal., 1985, 91, 54-63.

[33] Hanke, W.; Bie nert, R.; Jerschkewitz, H.G. Z. Anorg. Alg. Chem. 1975, 414, 109.

[34] Jhung, S.; Uh, Y.S. Chon, H. Synthesis and Characterization of Vanadium incorporated molecular sieve, VAPO-5.Appl. Catal., 1990, 62, 61-72.

[35] Kornatowski, J.; Wichterlova, B.; Roswadowski, M.; Baur, W.H Simultaneous occurrence of differently coordinated framework heteroatoms in one zeolite: MFI type vanadium silicalite, KVS-5. Stud. Surf. Sci. Catal., 1994, 84A, 117-124. 
[36] Montes, C.; Davis, M.E.; Murray, B.; Narayana, M. Isolated redox centres with in microporous environments 2: Vanadium containing aluminophosphate molecular sieve. J. Phys. Chem., 1990, 94, 6431-6435.

[37] Concepcion, J.M.; Lopez Nieto, A.; Mifsud, J.; Perez-Pariente, J. Synthesis, Characterization and catalytic properties of microporous MgVAPO-5. Appl. Catal. A: General, 1997, 151, 373-392.

[38] Nieto, J.M.L. Microporous and mesoporous materials with isolated vanadium species as selective catalysts in the gas phase oxidation reactions. Top. Catal., 2001, 15, 189-194.

[39] Perez, J.O. Borade, R.B.; Clearfield, A. Synthesis of a mesoporous aluminophosphate. J. Mol. Struct., 1998, 470, 221-230.

[40] Khimyak, Y.Z.; Klinowshi, J. Synthesis of meso structured aluminophosphates using cation templating synthetic mesoporous crystalline material. Phys. Chem. Chem. Phys. 2002, 2, 5275.

[41] Kresge, C.T.; Leonowicz, M.E.; Roth, W.J.; Vartuli, J.C. Synthetic Mesoporous Crystalline Material. US Pat. 5,098,684, 1992.

[42] Kaliaguine, S. Recent Advances and New Horizons in Zeolite Science and Technology in preconference summer school on zeolites. Taejon, 1996.

[43] Castro-Martins, S.D.; Khouzanpi, S.; Tuel, A.; Taarit, Y.B.; Mur, N.E.; Sellami, A. Characterization of titanium silicate using TS-1 modified carbon paste electrode. J. Electroanal. Chem., 1993, 350, 15-28.

[44] Castro-Martins, S.D. Tuel, A. Taarit, Y.B. Cyclic voltammetric characterization of Titanium silicate, TS-1. Zeolites, 1994, 14, 130136.
[45] Venkatathri, N.; Vinod, M.P.; Vijayamohanan, K.; Sivasanker, S. Cyclic voltammetric studies of Vanadium in V molecular sieves. $J$. Chem. Soc., Faraday Trans., 1996, 92, 473-478.

[46] Chatterjee, M.; Bhattacharya, D.; Venkatathri, N.; Sivasanker, S. Synthesis, Characterization and catalytic properties of two novel Vanado-alumino silicates with EU-1 and ZSM-22 structures. Catal. Lett., 1995, 35, 313-326.

[47] Gontier, S.; Tuel, A. Incorporation and stability of trivalent cations in mesoporous silicas prepared using primary amines and surfactant. Stud. Surf. Sci. Catal., 1997, 105, 29-36.

[48] Jahn, E.; Muller, D.; Wieker, W.; Richter-Mendau, J. On the synthesis of aluminophosphate molecular sieve $\mathrm{AlPO}_{4}-5$. Zeolites, 1989, 9, 177-181.

[49] Mertens, J.A.; Martens, M.; Grobet, P.J.; Jacobs, P.A. Innovation in Zeolite Materials Science. Grobet, P.J.; Mortier, W.J.; Vansant, E.F.; Schulz-Ekloff, G. Eds. Elsevier, Amsterdam, 97, 1988.

[50] Brunner, E.; Ernst, H.; Freude, D.; Hunger, M.; Pfeifer, H. in Innovation in Zeolite Materials Science. Grobet, P.J.; Mortier, W.J.; Vansant, E.F.; Schulz-Ekloff, G. Eds. Elsevier, Amsterdam, $155,1988$.

[51] Finger, G.; Jahn, E.; Zeigan, D.; Zibrowius, B.; Szulzewsky, K.; J. Richter-Mendau, J.; Bulow, M. Synthesis of Large-Sized Sapo-5 Crystals With Silicon Occupying Predominantly Phosphorus-TSites. Bull. Soc. Chim. Belges, 1989, 98, 291-295.

(C) Venkatathri et al.; Licensee Bentham Open.

This is an open access article licensed under the terms of the Creative Commons Attribution Non-Commercial License (http://creativecommons.org/licenses/by-nc/

3.0/) which permits unrestricted, non-commercial use, distribution and reproduction in any medium, provided the work is properly cited. 